\title{
AN APIGENIN GLUCOSIDE FROM Astragalus kadshorensis
}

M. D. Alaniya, N. F. Komissarenko, and

E. P. Kemertelidze

UDC 547.972.2

Six substances of flavonoid nature have been detected in the flowers of Astragalus kadshorensis Bunge, a plant endemic to Georgia, collected in the environs of Tbilisi. To isolate the flavonoids, the raw material was extracted with $80 \%$ methanol, the alcohol was evaporated off, the aqueous residue was purified with chloroform, and the low-polarity flavonoid glycosides and aglycones were extracted with ethyl acetate. The ethyl acetate extract was concentrated, and the residue was crystallized from acetone and then from ethanol. This gave yellow acicular crystals $(0.11 \%)$ with the composition $\mathrm{C}_{21} \mathrm{H}_{20} \mathrm{O}_{10}$, mp $239-$ $241^{\circ} \mathrm{C} ;[\alpha]_{\mathrm{D}}^{20}-50^{\circ}$ [c 1.0; ethanol-formamide (99:1)], $\mathrm{R}_{f} 0.44$ butanol-acetic acid-water (4:1:5)], giving all the reactions for flavonoids. In the cyanidin reaction the substance formed a red pigment which was not extracted by octanol. On the basis of the UV spectra obtained with complex-forming and ionizing reagents, the absence of a depression of the melting point of a mixture, and its mobility on paper chromatograms, the aglycone was identified as apigenin [1-3], and the initial substance as its 7-O- $\beta$-D-glucopyranoside, or cosmosiin [4].

\section{LITERATURE CITED}

1. V. T. Chernobai and D. G. Kolesnikov, Med. Prom. SSSR, $\underline{2}, 19$ (1966).

2. A. M. Pavlii and G. V. Makarova, Khim. Prirodn. Soedin., $\underline{6}, 761$ (1970).

3. M. Nogradi, L. Farkas, H. Wagner, and L. Hörhammer, Ber., $\underline{9}, 2783$ (1967).

4. T. A. Geissman, The Chemistry of Flavonoid Compounds, Pergamon Press (1962), p. 107.

I. G. Kutateladze Institute of Pharmacochemistry, Academy of Sciences of the Georgian SSR. Translated from Khimiya Prirodnykh Soedinenii, No. 4, pp. 527-528, July-August, 1971. Original article submitted March 30, 1971.

- 1973 Consultants Bureau, a division of Plenum Publishing Corporation, 227 West 17th Street, New York, N. Y. 10011. All rights reserved. This article cannot be reproduced for any purpose whatsoever without permission of the publisher. A copy of this article is available from the publisher for \$15.00. 